\title{
Acceptance of computers in human roles
}

\author{
Kylie O'Hare \& Ron Henderson \\ Centre for Applied Psychology \\ University of Canberra \\ ACT 2616 \\ Australia \\ ron@science.canberra.edu.au
}

\begin{abstract}
The aim of the study was to examine attitudes towards computers full filling what would be labelled traditional human roles. A total of 114 individuals completed a questionnaire examining their attitudes and the hypothesised predictors of attitudes. It was found that there was marked differences in attitudes toward computers full filling traditional human roles and that key psychological variables were statistically, but weakly, related towards these attitudes.
\end{abstract}

\section{KEY WORDS}

Anthropocentricism and computers, Computer acceptance, social issues.

\section{Introduction}

Researchers have began to examine peoples attitudes towards computers full filling human roles. The argument is now being advanced that although computer based technology may be capable of performing certain functions, do people want them to perform these functions, or are there roles that people do not want computers to perform.(see Nass, Lombard, Henrikson \& Steuer, 1995).

The current research aimed to examine peoples attitudes towards computers full filling what would traditionally been considered human roles in an Australian adult sample. The study also aimed to examine potential psychologically based predictors of these attitudes.

\section{METHOD}

\section{$2.1 \quad$ Subjects}

A total of 114 subjects voluntarily completed the self-report questionnaire. Subjects were from a range of occupations and background. Thirty-seven were male and 77 were female, with a mean age of 33. Seventy-nine percent of subjects used a computer on a daily basis.

\subsection{Measures}

The questionnaire assessed biographical data and a number of psychological attributes of the subjects. Section one assessed the participants cognitive attitudes towards general computer usage and three sub-scales from the Sixteen Personality Factor Questionnaire - Warmth, Abstractedness, and Apprehension which had previously been shown to be associated to acceptance of computers in nontraditional roles.

The final section of the questionnaire consisted of the acceptance of computers in human roles devised

Human-Computer Interaction: INTERACT'97 S. Howard, J. Hammond \& G. Lindgaard (editors)

Published by Chapman \& Hall OIFIP 1997 
by Nass et al., (1995). In this scale asked the question "Assume that computers could do everything that humans can do. How comfortable would you be with computers as..." The 24 items that followed named a different role, such as baby sitter, bank teller etc. The scale was scored on a five point (very uncomfortable / very comfortable) scale. A factor analysis on the current data set revealed that a four factor solution provided the best fit to the data (acceptance of computers in: routine roles, interpretive roles, authoritarian roles, personal roles).

\subsection{Procedure}

The non-probability technique of convenience sampling was used (Jackson, 1995), with questionnaires distributed to people of varying ages and occupations.

\section{Results}

A one-way Analysis of Variance (ANOVA) was conducted on the four factor mean scores to determine whether the sample differed with respect to their attitudes towards the factors. The ANOVA revealed a significant effect, $F(2,452)=63.36$, $\mathrm{p}<.001$. A post hoc comparison with a Bonferroni adjustment revealed that there were significant differences between acceptance of computers in interpretive roles and authoritarian and personal roles, with people being more accepting of computers in interpretive roles than in authoritarian or personal. There were also significant differences between acceptance of computers in routine roles and acceptance of computers in interpretive, authoritarian or personal roles. People were more accepting of computers in routine roles (see Table 1).

Table 1: Means and Standard Deviations of dimensions of Acceptance of Computers in human roles.

\begin{tabular}{lcc}
\hline Dimensions & Mean & SD \\
\hline Acceptance of computers in & & \\
$\quad$ routine roles & 3.14 & .90 \\
interpretive roles & 2.16 & .88 \\
authoritarian roles & 1.72 & .86 \\
personal roles & 1.82 & .83 \\
\hline
\end{tabular}

Stepwise regression analyses was conducted to identify predictors of attitudes towards acceptance computers in human roles. In the first analyses, cognitive attitudes was statistically selected to be entered on step 1 , and accounted for $4.5 \%$ of the variance of acceptance of computers in interpretive roles, $\mathrm{R}^{2}=.045, \mathrm{~F}(1,113)=5.36, \mathrm{p}<.05$.

Abstractedness also made a significant independent contribution, explaining a further $3.8 \%$ of the variance and was entered on step $2, \mathrm{R}^{2}=.083$, $\underline{F}(1,113)=5.03, \mathfrak{p}<.01$.

The second regression was conducted on acceptance of computers in authoritarian roles. Age was statistically selected to be entered on step 1 , and accounted for $4.3 \%$ of the variance, $R^{2}=.043$, $\mathrm{F}(1,113)=5.12, \mathrm{p}<.05$.

The regression run on factor three, acceptance of computers in personal roles, indicated that none of the independent variables were significantly responsible for the variance of acceptance of computers in these roles. The regression run on the acceptance of computers in routine roles indicated that $6.4 \%$ of the variance was caused by people's cognitive attitudes towards computers, $R^{2}=.064$, $\mathrm{F}(1,113)=7.72, \mathrm{p}<.01$.

\section{Discussion}

People appear to only accept computers acting in what could be considered routine roles. Acceptance of computer in authoritarian (e.g Judges) and personal (e.g baby sitters) was especially low. As would be expected cognitive attitudes were predictive of acceptance of computers in both interpretive and routine roles. It should be noted, however, that in all cases the amount of variance explained in the regression equation was low (under $10 \%$ ), indicating that other factors must account for a large portion of variance in human roles.

\section{References}

Nass, C. I., Lombard, M., Henriksen, L. \& Steuer, J. (1995). Anthropocentrism and computers.

Behaviour \& information Technology, 7, 103-135. 